\title{
ASSET MANAGEMENT TOOLS IN THE DIGITAL ENVIRONMENT
}

\author{
LAZAR D. GITELMAN, TATYANA B. GAVRILOVA \& MIKHAIL V. KOZHEVNIKOV \\ Academic Department of Energy and Industrial Enterprises Management Systems, \\ Ural Federal University, Russia
}

\begin{abstract}
The paper summarizes the changing approaches to asset management of manufacturing companies amid the unprecedented uncertainty in markets, progressing digital transformation and production facilities being enriched with intelligent information and communication systems. A conceptual model has been designed that reflects the new principles and the key conditions of asset management systems' operation in the digital industry. Having examined the cases of the energy sector and high-tech industries, the authors identify the main trends in the innovative development of production asset management: cutting-edge reliability-focused repair and maintenance methods, the digital twin technology, and platform solutions for business customization. The results of the study could be used for asset management strategy development in manufacturing and for improvement of the relevant legal and regulatory frameworks, including the international standards PAS 55 and ISO 55000.
\end{abstract}

Keywords: production and intellectual assets, unstable environment, digital transformation, repair and maintenance, digital twin, platform solutions, customization.

\section{INTRODUCTION}

ISO 55000:2014 defines asset management as "the coordinated activity of an organization to realise value from assets" [1]. This kind of activity implies reaching the balance of assetrelated performance, cost and risk and should accompany the whole lifecycle of an asset because with time, different components of the asset may change due to diverse factors. Competent asset management is crucial for meeting stakeholders' expectations within the existing budget constraints and/or ensuring compliance with the absolute (e.g. legal) restrictions.

Traditionally, asset management was focused on production assets, in particular fixed capital - long-term physical assets such as facilities, buildings, machinery and equipment, vehicles, and so on. In recent years, however, more attention has been given to intangibles assets that are not physical in nature - such as information and knowledge, results of R\&D, and intellectual property [2]. To perform well in a fast-changing and unpredictable environment, a company needs to adjust its strategy regularly, which, in its turn, requires a synchronous reaction on the part of the asset management system [3]. Digital transformation has made data, systems of data processing and analysis crucial for companies wishing to keep their competitive edge in the long run, thus increasing the significance of intangibles in business [4]. These systems support the exchange of data, communications and transactions for better engagement between different stakeholders. Moreover, although the significance of industrial assets in infrastructure sectors still remains very high, it is now not the fact of asset ownership as such that matters the most but the maximization of value for the consumer that could be achieved with the help of these assets.

Digital transformation and modern IT-systems have become pivotal to the success of businesses seeking to create value from assets in a turbulent world.

This study aims at systematizing the most significant changes in the approaches to asset management of industrial companies amid the unprecedented uncertainty of the market 
environment, digital transformation and enrichment of industrial production with intelligent data and communications systems.

\section{NEW PRINCIPLES OF ASSET MANAGEMENT}

The general requirements to the asset management system are described in the well-known international standard PAS 55 [5], [6]. PAS 55 outlines the types of activities that are necessary for efficient asset management and for evaluation of the assets' current condition. The Standard is of non-regulatory nature: it provides guidelines on how to improve the asset management policy and eventually optimize all management processes in the organization as a whole.

PAS 55 is based on the use of the Plan-Do-Check-Act (PDCA) cycle (see Fig. 1): the development of an asset management system should start with formulating the principles of the technical policy, devising a long-term strategy and setting goals regarding the results, risks and costs, and drawing long-term plans, which should correspond to the expectations of asset owners and other stakeholders.

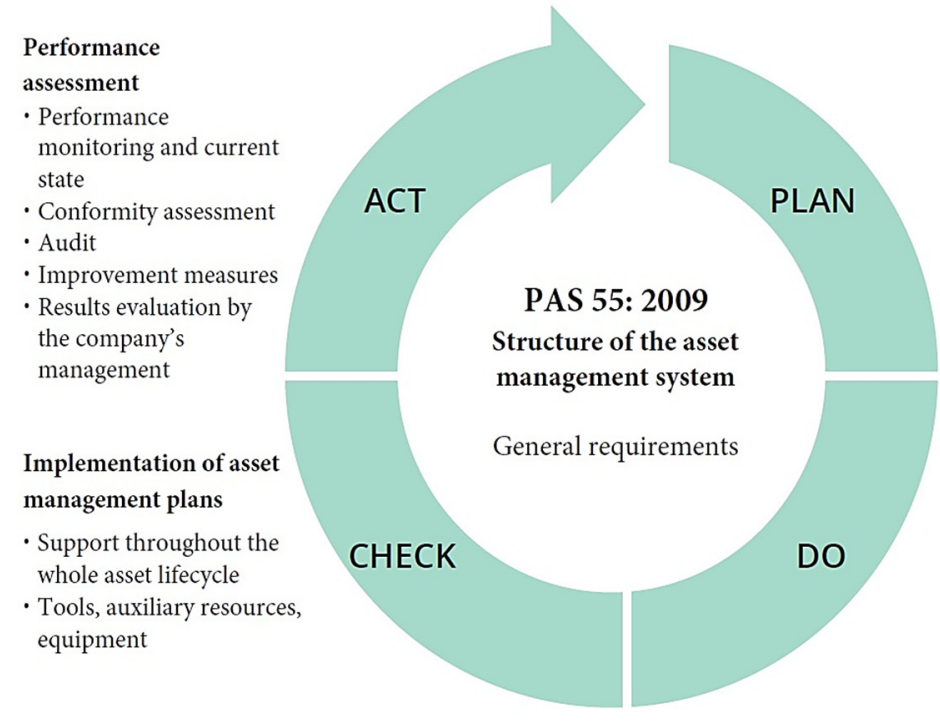

Figure 1: PDCA cycle according to PAS 55.
Asset management

- Strategy, goals and plans

- Developing an emergency action plan

\section{Means of asset}

management

- Structure, rights and responsibilities

- Documentation of the asset management system

- Information management

- Risk management

- Legal support

- Change management

- Personnel training and competency development

- Outsourcing of asset management functions

In our view, as digital transformation is becoming faster and more large-scale, the range of requirements to asset management is becoming broader and new principles and tools are being introduced to asset management activities.

1. Within an organization, the asset management system should be working in sync with other management systems (see Fig. 2). If an asset management system comprises assets of all types (that is, apart from physical assets, it includes intangible, financial, information and human resources), it is necessary to ensure effective coordination of all these subsystems and communication between them. The latter is based on an information infrastructure that needs to be constantly improved. Such infrastructure should include the knowledge management function, that is, the knowledge of the company's assets and the related processes, operations and regulations. 
2. To select the main assets for production and improvement of the key products and services, the platform and modular principles are applied. Assets whose impact on the technological architecture of products is minimal should be replaceable easily and cheaply.

3. The asset management system maintains real-time access to the data on the retrospective and current state of the company's assets. Predictive analytics tools, big data technologies and robotic tools can be used for prediction and prevention of machine failure.

4. For optimization of the overall performance - the value gained from assets, it is necessary to identify the trade-offs between different factors (results, costs and risks) considered throughout the whole asset lifecycle. The potential growth in the complexity of assets throughout their life, the increasing uncertainty of the external environment make expert communications even more important. Expert communications include specialized research, continuous personnel training, and organization of interdisciplinary teams.

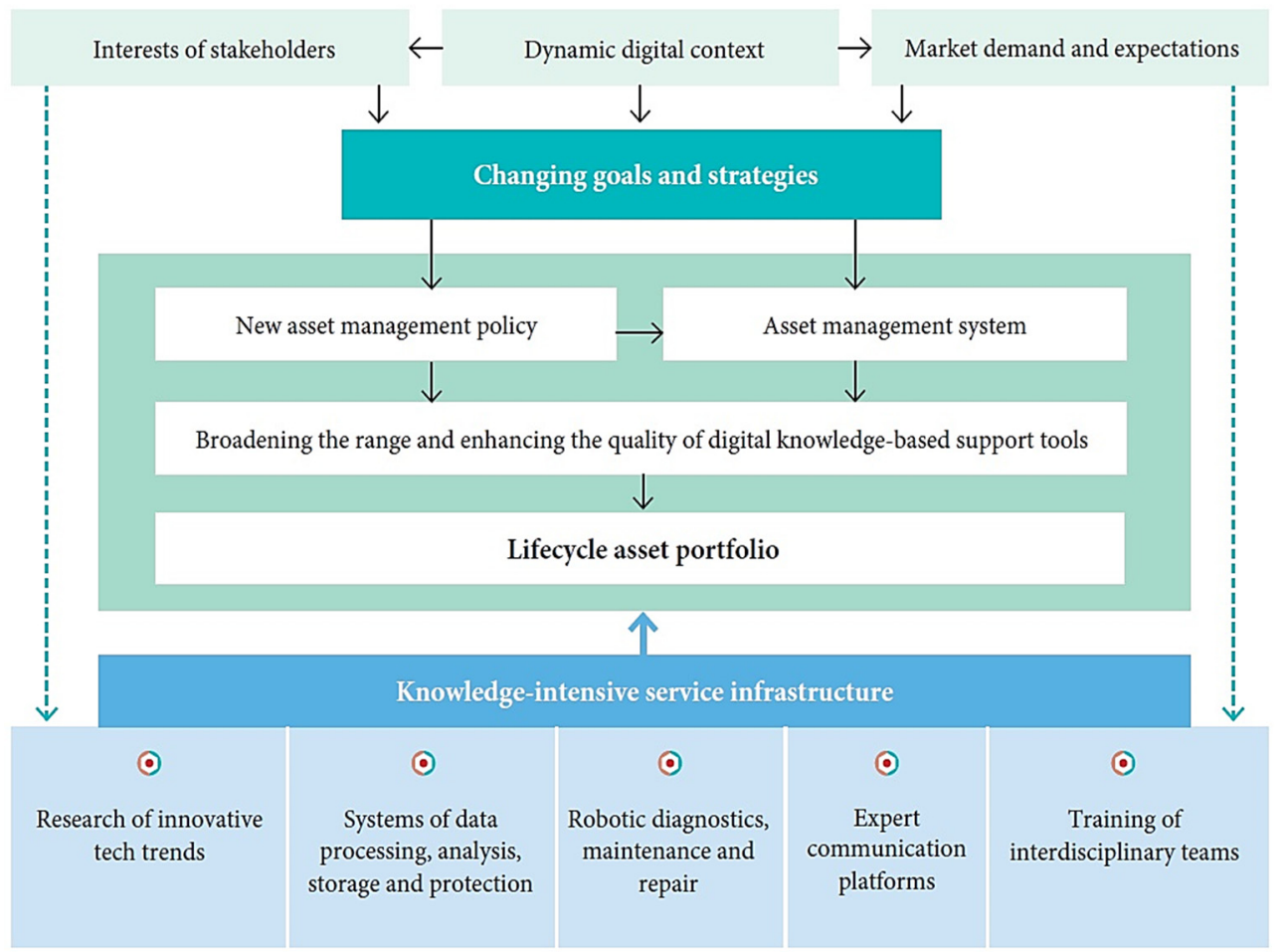

Figure 2: Connections between the key elements of the asset management system.

The main conditions that determine the successful operation of an asset management system are as follows:

- Effective coordination of the asset management policy and ensuring its compliance with the company's general strategy and digital transformation goals. 
- Flexible organization culture; the company's ability to ensure efficient communication with consultants, stakeholders and professional communities.

- Coordination of plans for development and digitization of asset subsystems of various types.

- Good internal communications between specialists of different subsystems; crossfunctional coordination, including platform-based coordination.

- High levels of competency and sufficient experience of the staff working in the system of asset management; organization of staff training for non-standard problem-solving.

- High quality of information support and its compliance with the decision justification requirements, including big data analytics and availability of information about the state of the assets, their characteristics, risks and costs.

- Complete data accessibility; the speed of data transfer and keeping the knowledge management system updated from different sources.

\section{EMERGING OPPORTUNITIES IN ASSET MANAGEMENT TECHNIQUES}

At the lower level (management of individual assets throughout their lifecycle), the most advanced approach is to switch from the scheduled preventive maintenance (SPM) system to condition-based maintenance (CBM). The CBM approach results in reduced maintenance and repair costs, it helps minimize the risks of unforeseen breakdowns between overhauls, and improve the performance of machines and equipment. With regard to the abovementioned considerations, the key factor of success is the quality of the diagnostics system (preferably continuous automated control over the parameters of the equipment's state) and IT-support.

Regarding the development of strategies of asset use, one of the most advanced methodologies is the RCM or reliability-centred maintenance, which can be helpful to choose the most suitable failure management policy. The primary idea behind the RCM methodology is that the rules of equipment maintenance are determined not only by the nature and characteristics of failure but mainly by its consequences [7]. A failure management policy may include predictive or preventive maintenance, changes in the operational rules and regulations, changes in the design or configuration of the system, and other measures aimed at mitigating the effect of a technical failure [8]. These measures may also include changes in the methods of conducting certain maintenance and repair works and personnel training.

Higher levels of the asset management system require a methodology for asset system creation by following the corporate strategy and asset management policy. It is, therefore, necessary to distinguish between critical and non-critical assets or systems of assets. Critical assets, in their turn, require special means for sustaining their smooth performance and include ensuring preparedness of emergency equipment, personnel training (e.g. regular emergency drills and exercises followed by on-site discussions and analysis), and emergency plans.

The asset management system implies design, implementation and support of the information infrastructure, whose purpose is to provide all the key stakeholders with access to all the necessary data. These data may include registers of assets, drawings, agreements, licenses, and documents specifying regulatory requirements, policies, standards, directives, data on the state of assets and their productivity, and employees' undocumented knowledge. Information about this or that asset is usually communicated from the lowest level of asset operations. 
There is intensive information exchange both inside the organization and between the organization and external stakeholders (consultants, specialist communities, and partners), based on a wide range of tools and methods.

Companies can benefit from the technologies for real-time monitoring of assets, which allow to gain situational awareness much faster than before. Through analysis of retrospective and current data and the use of special prognostic tools, it is now possible to predict the failure of machines or their parts and thus optimize the costs of maintenance and repair in the future. As a result, risk- and efficiency-based asset management strategies are becoming more widely spread [9], [10]. Such strategies are particularly relevant in relation to critical infrastructure, where emergency situations, such as unexpected asset failure may lead to huge financial and reputation losses and in some cases have even more disastrous consequences of the technogenic, social and economic nature.

To implement a risk-based asset management strategy, modern risk management analysis tools are necessary, such as robotic devices, gaining popularity in power engineering for intellectual monitoring of electrical power and heat networks [11]. For example, drones equipped with sensors, cameras and intelligent software can be used for inspection of high voltage electrical lines. They are able to detect damages and send this information to the dispatcher. This way the difficult and time-consuming work of powerline inspection is done remotely with drones being able to access the most hard-to-rich places, capturing a wealth of data, finding and assessing damage. The use of drones has increased the accuracy of powerline inspections since many damaged spots are usually hidden from human vision.

Together with the growing digitization of the asset management sphere, there is a growing need for digital management asset (DAM) systems, combining data processing, storage and distribution, management of knowledge and digital content [12]. DAM systems encompass not only equipment and fixed assets but can also apply to asset management in the broadest sense - to organizations in different sectors (e.g. industry, public services, finance and investment), for control and regulation on the level of individual companies or on the national and even global scale [13].

To create and develop a DAM system, substantial IT-support is required, including software and hardware and qualified personnel. The majority of organizations go for outsourcing as the most evident solution, that is, they buy the services of SaaS data centres (SaaS - Software as a Service). Large organizations which make extensive use of information technologies and offer IT-services to their customers create data centres of their own. In order to provide an adequate level of data management, companies purchasing cloud services employ qualified IT-specialists to maintain efficient communication with service providers, ensure cyber security, and develop IT-strategies.

A real breakthrough in digital management was the development of the digital twin. The digital twin is a virtual interactive copy of a real physical object, product, technological process or production in general [14]. For example, a digital twin of a manufacturing facility can model the location of the machines, staff flow, operational processes and emergencies. The functions of a digital twin are not limited only to the collection of data acquired during the development and manufacturing of a system (product). In fact, the digital twin continues gathering and analysing information throughout the whole lifecycle of the real object, for example, with the help of IoT technologies.

This tool is quite expensive to implement, although for large corporations engaged in long and capital-intensive investment projects digital twins pay off multiple times. For example, thanks to the interactive analysis of the data from the digital twin by Schneider Electric, one of the European oil refineries had received a warning of potential compressor failure 25 days before it actually happened. The company thus managed to save several millions of dollars 
through the digital twin concept married with technologies of big data analysis, AI, machine learning, and industrial IoT [15]. Another example is General Electric's Digital Twin - a corporate system for control over a power generation company's performance. The principle behind this system is the development of a behavioural digital twin of an asset (usually equipment): a mathematical model is created for analysis of the asset's behaviour [16].

There are different types of digital twins developed for specific processes. For instance, ABB's system of data acquisition and processing Transformer Electronic Control is applied in electric power engineering to monitor temperature and currents and create thermal models for transformers and voltage regulation. These models calculate the most heated points in accordance with the standards of the International Electrotechnical Commission and Institute of Electrical and Electronics Engineers. They are also used for modelling of entire thermal behaviour, which allows to compare the measured and expected values.

A novel perspective on asset management is offered by the developing platform approach. Platform is understood as a set of various assets (equipment, processes, knowledge, people and relationships) used to create a portfolio of products and services able to change their value, consumer properties and functions as new product components are promptly added or old and irrelevant are removed [17].

To construct the necessary set of assets, the modular approach is applied, which distinguishes between two types of assets - basic and variable. Basic assets are important for the creation of a unique technological architecture of products - the key competitive advantage of the company. Variable assets are pivotal to the production of additional (complementary) services and also maintain the overall stability and efficiency of the asset system.

Pioneers of the platform model are the companies which in fact possess no physical assets such as Uber, Airbnb and Facebook. Online platforms are now making deep inroads into such industries as heavy engineering, aerospace engineering, mining and electronics, and power engineering [18]. The main reason behind this growing interest in platforms in the industrial sector is the increasing demand for customization. Enterprises that used to be orientated towards serial, standardized production are now seeking to manufacture unique products, in other words, to become original equipment manufacturers.

For companies transferring to platform solutions, however, there is a risk of making the wrong decisions regarding the choice of assets that would enable them in the long-term to manufacture sufficient quantities of high-tech, adaptive products without having to make large investment or attract considerable external funding [19]. The choice of the assets that would enable the company to adopt a platform model is a crucial moment which happens at the very beginning of the platform's lifecycle. It is important that such a model should align together the strategy of asset management, corporate and product strategies.

The process of improvement of an asset management system with regard to the innovations described above is illustrated in Fig. 3. This process comprises two parts. First, the asset management system is formed. It goes hand in hand with the continuous strategic process to ensure active knowledge exchange and communications between various stakeholders as well as non-stop monitoring of the external environment. This stage results in the use of proactive training solutions to encourage employees to participate in innovation activities. Second, it is necessary to ensure expanded and more intensified use of digital instruments in asset management, including platform technologies and interdisciplinary team interactions. In other words, the focus is made on the stimulation of active interactions between manufacturers and consumers within value networks. The organization thus becomes more adaptable and responsive to the changes in the turbulent external environment, bringing about a whole host of competitive advantages. 


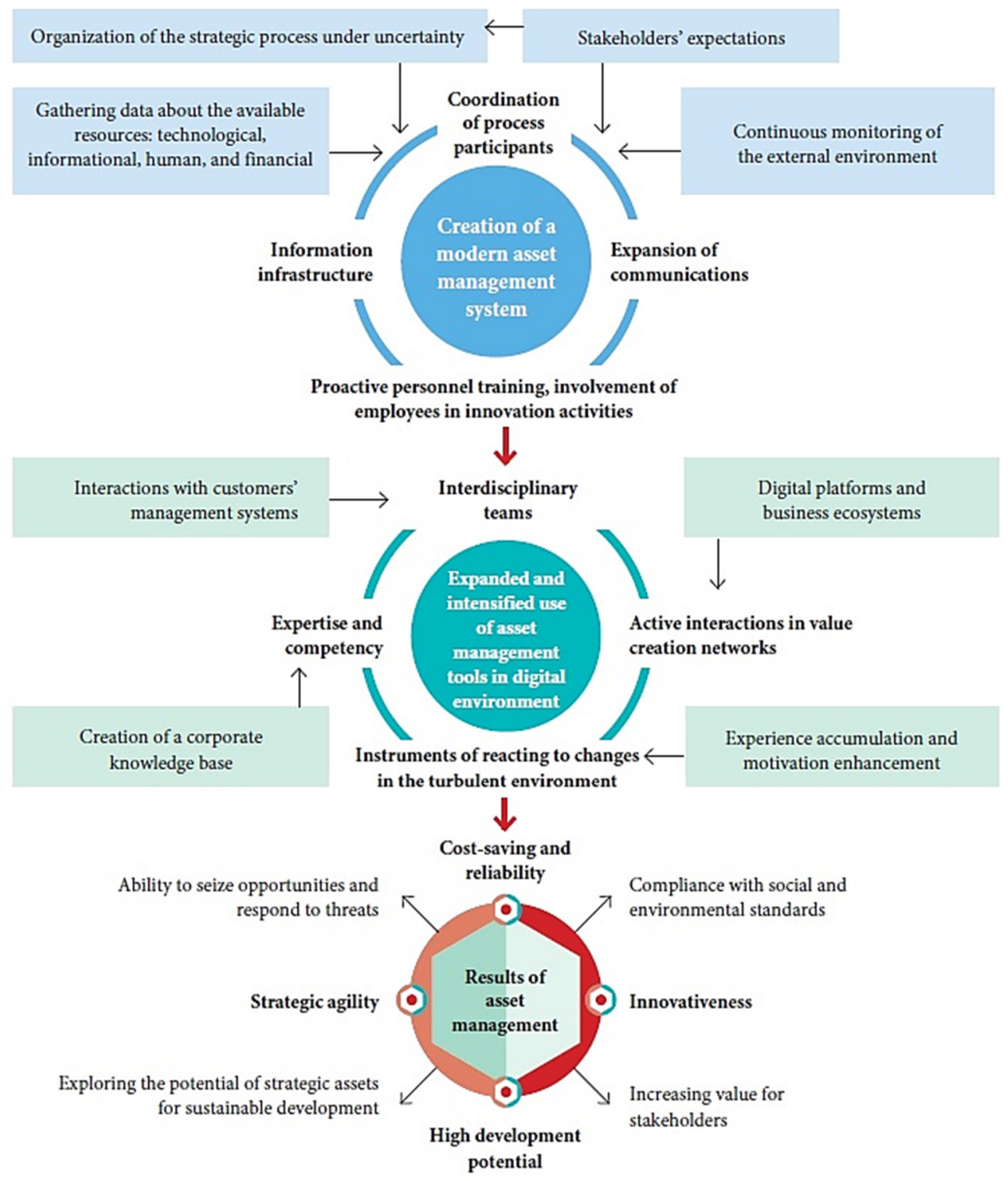

Figure 3: Improvement of the asset management system in a changing environment.

The creation and development of an advanced asset management system puts heavy demands on the personnel's skills and knowledge. Organization of asset management education for the staff, intensive internal communications, formation of interdisciplinary teams, continuous training, analysis of the lessons learnt from previous experience, learning from external sources, creation and development of the knowledge management system constitute the core of asset management practices.

It is best that training in asset management should follow the logic described below. 
At the first stage, it is important to demonstrate that digital transformation implies keeping constantly updated about the context and content of the necessary competencies, which means mastering new knowledge, practices and methods of work and using them to replace the obsolete ones. All of the above is a key to successful work in a digital environment. Special attention should be given to the skills of systems thinking, systems engineering and to the methods of efficient communication within interdisciplinary teams.

The asset management system cannot function efficiently without reliable and extensive information support and intensive knowledge accumulation and exchange. The second stage, therefore, includes the disciplines that deal with the characteristics of information, knowledge and experience necessary for decision-making and the modern information support systems for asset management processes. Training also covers modes of communication, platform tools, tech eco-systems, interactions with IT-providers and matters of cyber security.

The third stage focuses on the methods of forecasting and planning under uncertainty, risk assessment and means of enhancing asset reliability and adaptability.

The list of options recommended for personnel training depending on the particular jobs they do was proposed by the Global Forum on Maintenance and Asset Management (GFMAM). The list contains 6 groups of subjects and 39 disciplines that together form the structure of asset management competencies (Table 1).

Table 1: Examples of disciplines included into the field of asset management [20].

\begin{tabular}{|l|l|}
\hline Groups of subjects & Disciplines \\
\hline Strategy and planning & $\begin{array}{l}\text { Asset management policy/Demand analysis/Principles of } \\
\text { strategic and operational planning }\end{array}$ \\
\hline Decision-making & $\begin{array}{l}\text { Lifecycle value realization/Resourcing strategy, Capital } \\
\text { investment/Shutdown and outage strategy }\end{array}$ \\
\hline Lifecycle delivery & $\begin{array}{l}\text { Legislation and technical regulations/Systems engineering/ } \\
\text { Configuration management/Operations, maintenance and } \\
\text { repair/Modernization and decommissioning of assets }\end{array}$ \\
\hline Information support & $\begin{array}{l}\text { Information systems of asset management/Asset information } \\
\text { standards }\end{array}$ \\
\hline $\begin{array}{l}\text { Organization structure } \\
\text { and personnel }\end{array}$ & Leadership/Competency and behaviour management \\
\hline Risks and analysis & $\begin{array}{l}\text { Fault and incident response/Management of change/ } \\
\text { Sustainable development/Stakeholder engagement }\end{array}$ \\
\hline
\end{tabular}

\section{CONCLUSIONS}

Companies embracing digital transformation can maximize the efficiency of their value chains based on asset lifecycle management: from planning and design through development to processes of operation and maintenance. Digital solutions enable companies to ensure asset observability and relatively predictable operational failure-free performance. Cloud-based computing, industrial Internet of Things, and AI are transforming traditional industrial operations and offer companies unprecedented opportunities of business growth. This, of course, also brings about new risks and uncertainty to companies' activities on the market, such as cyber security risks and breaches of confidentiality. Enterprises will face the challenging task of balancing their production processing, from operations planning to real- 
time equipment and facility management, to meet the existing operational performance constraints in order to achieve the best possible investment payoff.

Our experience with large energy companies has led us to the conclusion that modernization of asset management systems should include the following key components.

1. Assessment of the company management's readiness to digitize their business, which includes estimation of the capital investments required to implement smart production technologies.

2. Asset inventory, assessment of the assets' actual state (including physical wear and tear and obsolescence) and of their compatibility with the modern digital solutions.

3. Analysis of different scenarios of asset digitization and estimation of the impact that digitization will have on various business processes; estimation of the company's overall performance, including cost-saving, operating profit, emergency repair costs.

4. Proactive personnel training, including training aimed at developing engineering management and engineering economic competencies.

\section{ACKNOWLEDGEMENT}

The work was supported by Act 211 Government of the Russian Federation, contract No. 02.A03.21.0006.

\section{REFERENCES}

[1] ISO 55000:2014, Asset management - Overview, principles and terminology. https://www.iso.org/obp/ui/\#iso:std:iso:55000:ed-1:v2:en. Accessed on: 20 May 2021.

[2] Gavrikova, E., Volkova, I. \& Burda, Y., Strategic aspects of asset management: An overview of current research. Sustainability, 12, p. 5955, 2020.

[3] Maletič, D., Maletič, M., Al-Najjar, B. \& Gomišček, B., Development of a model linking physical asset management to sustainability performance: An empirical research. Sustainability, 10, p. 4759, 2018.

[4] Asset Management 2020, A brave New World. https://www.pwc.com/gx/en/assetmanagement/publications/pdfs/pwc-asset-management-2020-a-brave-new-worldfinal.pdf. Accessed on: 20 May 2021.

[5] PAS 55-1:2008, Asset management. Part 1: Specification for the optimized management of physical assets, http://www.irantpm.ir/wp-content/uploads/2014/01/ pass55-2008.pdf. Accessed on: 20 May 2021.

[6] PAS 55-2:2008, Asset management. Part 2: Guidelines for application of PAS 55-1. http://www.irantpm.ir/wp-content/uploads/2014/01/pass55guide.pdf. Accessed on: 20 May 2021.

[7] Moubray, J., Reliability-Centered Maintenance. 2nd ed., Industrial Press Inc.: New York, 1997.

[8] Gitelman, L.D., Kozhevnikov, M.V., Chebotareva, G.S. \& Kaimanova, O.A., Asset management of energy company based on risk-oriented strategy. WIT Transactions on Ecology and the Environment, vol. 246, WIT Press: Southampton and Boston, pp. 125-135, 2020.

[9] Candón, E. et al., Implementing intelligent asset management systems (IAMS) within an Industry 4.0 manufacturing environment. IFAC-PapersOnLine, 52(13), pp. 24882493, 2019.

[10] Aronson, K.E., Murmansky, B.E., Murmanskii, I.B. \& Brodov, Y.M., An expert system for diagnostics and estimation of steam turbine components' condition. International Journal of Energy Production and Management, 5(1), pp. 70-81, 2020. 
[11] Gitelman, L.D., Kozhevnikov, M.V. \& Kaplin, D.D., Asset management in grid companies using integrated diagnostic devices. International Journal of Energy Production and Management, 4(3), pp. 230-243, 2019.

[12] Digital asset management - A closer look at the literature. http://citeseerx.ist.psu.edu/ viewdoc/download?doi=10.1.1.369.7294\&rep=rep1\&type=pdf. Accessed on: 20 May 2021.

[13] Haberly, D., MacDonald-Korth, D., Urban, M. \& Wójcik, D., Asset management as a digital platform industry: A global financial network perspective. Geoforum, 106, pp. 167-181, 2019.

[14] Macchi, M., Roda, I., Negri, E. \& Fumagalli, L., Exploring the role of digital twin for asset lifecycle management. IFAC-PapersOnLine, 51(11), pp. 790-795, 2018.

[15] Digital twin: Bring your data to life for better performance. https://www.se.com/us/en/ download/document/DT_eguide_09-10-19AR0_EN/. Accessed on: 20 May 2021.

[16] GE Digital Twin. Analytic engine for the digital power plant. https://www.ge.com/ digital/sites/default/files/download_assets/Digital-Twin-for-the-digital-power-plant.pdf. Accessed on: 20 May 2021.

[17] Robertson, D. \& Ulrich, K., Planning for product platforms. Sloan Management Review, 39(4), pp. 19-31, 1998.

[18] Gitelman, L.D., Kozhevnikov, M.V. \& Sandler, D.G., Technology platforms as a tool for solving complex innovation problems. International Journal of Design and Nature and Ecodynamics, 11(4), pp. 584-592, 2016.

[19] André, S. \& Elgh, F., Modeling of transdisciplinary engineering assets using the design platform approach for improved customization ability. Advanced Engineering Informatics, 38, pp. 277-290, 2018.

[20] The Asset Management Landscape, 2nd ed., 2014. https://www.gfmam.org/sites/ default/files/2019-05/GFMAMLandscape_SecondEdition_English.pdf. Accessed on: 20 May 2021. 